\title{
Correction to: In the South African setting, HIV-associated Burkitt lymphoma is associated with frequent leukaemic presentation, complex cytogenetic karyotypes, and adverse clinical outcomes
}

\author{
Jessica Opie ${ }^{1} \cdot$ Katherine Antel $^{2} \cdot$ Ania Koller $^{1} \cdot$ Nicolas Novitzky $^{1}$
}

Published online: 19 February 2020

(C) Springer-Verlag GmbH Germany, part of Springer Nature 2020

\section{Correction to: Annals of Hematology}

https://doi.org/10.1007/s00277-020-03908-8

The article "In the South African setting, HIV-associated Burkitt lymphoma is associated with frequent leukaemic presentation, complex cytogenetic karyotypes, and adverse clinical outcomes", written by Jessica Opie, Katherine Antel, Ania Koller and Nicolas Novitzky, was originally published online on December 02, 2019 with Open Access under a Creative Commons Attribution (CC BY) license 4.0.

With the authors' decision to cancel Open Access the copyright of the article changed on February 2020 to (C) Springer-Verlag GmbH Germany, part of Springer Nature 2020 with all rights reserved.

The original article has been corrected.

Publisher's note Springer Nature remains neutral with regard to jurisdictional claims in published maps and institutional affiliations.

The online version of the original article can be found at https://doi.org/ $10.1007 /$ s00277-020-03908-8

Jessica Opie

jessica.opie@uct.ac.za

1 Division of Haematology, Department of Pathology, Faculty of Health Sciences, University of Cape Town and National Health Laboratory Service, Groote Schuur Hospital, Cape Town, South Africa

2 Division of Clinical Haematology, Department of Medicine, Faculty of Health Sciences, University of Cape Town and Groote Schuur Hospital, Cape Town, South Africa 